\title{
Factors influencing the latency of simple reaction time
}

\author{
David L. Woods ${ }^{1,2,3,4 *}$, John M. Wyma ${ }^{1}$, E. William Yund ${ }^{1}$, Timothy J. Herron ${ }^{1}$ and \\ Bruce Reed 2,5 \\ ${ }^{1}$ Human Cognitive Neurophysiology Laboratory, Veterans Affairs Northern California Health Care System, Martinez, CA, \\ USA, ${ }^{2}$ The Department of Neurology, University of California Sacramento, Davis, CA, USA, ${ }^{3}$ Center for Neurosciences, \\ University of California Davis, Davis, CA, USA, ${ }^{4}$ Center for Mind and Brain, University of California Davis, Davis, CA, USA, \\ ${ }^{5}$ Alzheimer's Disease Center, Department of Neurology, University of California Davis, Davis, CA, USA
}

\section{OPEN ACCESS}

Edited by:

Guillaume A. Rousselet,

University of Glasgow, UK

Reviewed by:

Eric-Jan Wagenmakers, University of Amsterdam, Netherlands

Stuart J. Ritchie,

The University of Edinburgh, UK

*Correspondence:

David L. Woods,

Human Cognitive Neurophysiology Laboratory, Veterans Affairs Northern

California Health Care System, 150 Muir Road, Martinez, CA 95553,

dlwoods@ucdavis.edu

Received: 02 January 2015 Accepted: 26 February 2015 Published: 26 March 2015

Citation:

Woods DL, Wyma JM, Yund EW Herron TJ and Reed B (2015) Factors influencing the latency of simple reaction time.

Front. Hum. Neurosci. 9:131. doi: 10.3389/fnhum.2015.00131
Simple reaction time (SRT), the minimal time needed to respond to a stimulus, is a basic measure of processing speed. SRTs were first measured by Francis Galton in the 19th century, who reported visual SRT latencies below 190 ms in young subjects. However, recent large-scale studies have reported substantially increased SRT latencies that differ markedly in different laboratories, in part due to timing delays introduced by the computer hardware and software used for SRT measurement. We developed a calibrated and temporally precise SRT test to analyze the factors that influence SRT latencies in a paradigm where visual stimuli were presented to the left or right hemifield at varying stimulus onset asynchronies (SOAs). Experiment 1 examined a community sample of 1469 subjects ranging in age from 18 to 65. Mean SRT latencies were short (231, $213 \mathrm{~ms}$ when corrected for hardware delays) and increased significantly with age $(0.55 \mathrm{~ms} /$ year), but were unaffected by sex or education. As in previous studies, SRTs were prolonged at shorter SOAs and were slightly faster for stimuli presented in the visual field contralateral to the responding hand. Stimulus detection time (SDT) was estimated by subtracting movement initiation time, measured in a speeded finger tapping test, from SRTs. SDT latencies averaged $131 \mathrm{~ms}$ and were unaffected by age. Experiment 2 tested 189 subjects ranging in age from 18 to 82 years in a different laboratory using a larger range of SOAs. Both SRTs and SDTs were slightly prolonged (by $7 \mathrm{~ms}$ ). SRT latencies increased with age while SDT latencies remained stable. Precise computer-based measurements of SRT latencies show that processing speed is as fast in contemporary populations as in the Victorian era, and that age-related increases in SRT latencies are due primarily to slowed motor output.

Keywords: gender, timing, processing speed, motor, foreperiod, handedness, hemisphere, replication

\section{Introduction}

Simple reaction time (SRT) tests, where subjects simply respond as fast as possible to the occurrence of a stimulus, are among the most basic measures of processing speed. SRTs were first studied by Francis Galton in the late 19th century (Johnson et al., 1985). More recent studies have shown significant correlations between SRT latencies of processing speed and measures of fluid intelligence (Deary et al., 2001; Sheppard and Vernon, 2008). Indeed, Jensen (2011) argued that SRT latencies provide one of the most objective metrics for comparing processing speed, and hence fluid intelligence, across different populations. 
In a recent historical meta-analysis, Silverman (2010) found that SRT latencies have increased substantially since the Victorian era. For example, in studies performed from 1884 to 1893 , Francis Galton recorded visual SRT latencies that ranged from 181 to $189 \mathrm{~ms}$ in subjects ranging in age from 18 to 60 years (Johnson et al., 1985). These latencies are considerably shorter than those reported in recent SRT studies (Lowe and Rabbitt, 1998; Deary et al., 2001; Deary and Der, 2005; Der and Deary, 2006). Given the correlation between SRTs and fluid intelligence (Deary et al., 2001; Bugg et al., 2006), Woodley et al. (2013) concluded that the slowed SRTs in recent studies reflected a systematic reduction in processing speed, and hence fluid intelligence, in contemporary populations.

However, an alternative explanation of the apparent SRT slowing is that the SRT latencies reported in recent studies have been inflated by hardware and software delays in computerbased paradigms (Dordonova and Dordonov, 2013). In support of this argument, contemporary studies using mechanical SRT measurements (Montare, 2010; Eckner et al., 2011), including SRT testing procedures similar to those used by Galton (Dordonova and Dordonov, 2013), report SRT latencies similar to those observed in the Victorian era.

This line of reasoning implies that SRT latencies have been consistently overestimated in computer-based studies performed over the past several decades. Table 1 provides a summary of recent large-scale SRT studies: none of the contemporary, computer-based studies reported SRT latencies as short as those reported by Galton. However, mean SRT latencies reported in recent studies vary widely (Table 1), ranging from $233 \mathrm{~ms}$ (Krieg et al., 2001; Vincent et al., 2012) to nearly $400 \mathrm{~ms}$ (Bugg et al., 2006). These variations suggest that the magnitude of SRT overestimation may vary as a function of the paradigm and the computer system used for testing. One possible explanation for these variations is variable timing delays introduced by computer hardware and software that can increase measured SRT latencies by up to $100 \mathrm{~ms}$ (Neath et al., 2011). Therefore, in the current experiments, we used carefully calibrated computer hardware and high-precision computer software (see methods) that provided accurate computer-based SRT latency measurements, enabling corrections for hardware and software delays.

The improved computer-based paradigm was used to analyze the effects of factors that have been found to significantly influence SRTs, including age, sex, and education. Previous studies have uniformly found significant age-related increases in SRT latencies (Wilkinson and Allison, 1989; Fozard et al., 1994; Inui, 1997; Anstey et al., 2005; Commodari and Guarnera, 2008; Deary et al., 2010; Godefroy et al., 2010; Era et al., 2011; Dykiert et al., 2012a; see Table 1). Increasing age has also been associated with increases in trial-to-trial SRT variance (Dykiert et al., 2012a; Bielak et al., 2014). However, the nature of age-related increases in SRTs remains incompletely understood. Increasing age could influence SRTs at two possible processing stages: (1) older subjects could take longer to detect a stimulus, and (2) older subjects could take longer to produce a response once a stimulus has been detected. In the current experiments, we were able to divide the SRT into stimulus detection time (SDT), the time needed to perceive the stimulus, and movement initiation time (MIT), the time needed to depress the response button, by subtracting an independent measure of MIT from the SRT of each subject.

Previous studies have also reported significant SRT differences between the sexes, with men generally showing shorterlatency SRTs than women (Krieg et al., 2001; Anstey et al., 2005; Era et al., 2011; Dykiert et al., 2012b; Vincent et al., 2012), although these effects are smaller and less consistent than age effects (Sheppard and Vernon, 2008). In addition, subjects with increased education generally have shorter-latency SRTs (Krieg et al., 2001; Anstey et al., 2005), although such effects are small or absent in some populations (Vincent et al., 2012; Ritchie et al., 2013).

We also analyzed the effects of two stimulus variables; preceding stimulus onset asynchrony (SOA) and the hemifield of presentation. When stimuli are presented at varying intervals, SRT latencies are strongly influenced by the preceding SOA, with shorter-latency SRTs obtained for stimuli delivered at longer SOAs (Niemi and Naatanen, 1981). Some studies have

TABLE 1 | Studies of age-related changes in visual simple reaction time (SRT).

\begin{tabular}{|c|c|c|c|c|c|c|c|c|c|}
\hline Study & $\mathbf{N}$ & Age range & SRT (ms) & $\mathrm{SD}(\mathrm{ms})$ & IS-SD (ms) & CV (\%) & Age slope & SOA & No. trials \\
\hline Bugg et al. (2006) & 196 & $20-89$ & 397 & 142 & & & & & $32(0)$ \\
\hline Deary et al. (2001) & 900 & 55 & 358 & 120 & 91 & $26 \%$ & & $1-3 s$ & $20(8)$ \\
\hline Deary et al. (2011) box & 150 & $18-80$ & 256 & 38 & 50 & $20 \%$ & 0.80 & $1-3 s$ & $20(8)$ \\
\hline Deary et al. (2011) PC & 150 & $18-80$ & 274 & 49 & 45 & $16 \%$ & 1.00 & $1-3 s$ & $20(8)$ \\
\hline Reeves et al. (2006) & 2,261 & $17-46$ & 285 & 67 & 94 & $33 \%$ & 1.10 & $0.5-1.8 \mathrm{~s}$ & 25 \\
\hline Vincent et al. (2008) & 5,247 & $18-51$ & 267 & 74 & & & 1.20 & $1-2 s$ & $40 \times 2$ \\
\hline Vincent et al. (2012) & 107,413 & $17-65$ & 261 & 47 & & & 0.52 & $1-2 s$ & $40 \times 2$ \\
\hline Experiment 1 & 1,469 & $18-65$ & 231 & 27 & 40 & $17 \%$ & 0.55 & $1-1.8 \mathrm{~s}$ & $120(20)$ \\
\hline Experiment 2 & 189 & $18-82$ & 238 & 28 & 53 & $22 \%$ & 0.45 & $1-2 s$ & $100(20)$ \\
\hline
\end{tabular}

N, number of participants; SD, intersubject standard deviation; IS-SD, intrasubject (trial-to-trial) standard deviation; CV, coefficient of variation (IS-SD/SRT); Age-slope, estimated rate of increase in SRTs in ms/year; SOA, range of stimulus onset asynchrony; No. trials, number of trials, with the number of practice trials in parentheses. 
also suggested that these foreperiod effects are altered in older subjects (Bherer and Belleville, 2004; Vallesi et al., 2009), while other studies find similar effects in subjects of different ages (Greenwood et al., 1993).

Simple reaction time latencies to stimuli presented to the left and right hemifield also vary: SRTs are slightly faster to stimuli that are delivered to the visual field contralateral to the hand used in responding, which directly activates the hemisphere controlling motor responses, and therefore avoids the additional delay associated with callosal transmission (Clarke and Zaidel, 1989; Bisiacchi et al., 1994; Brizzolara et al., 1994; Chaumillon et al., 2014). Some studies have also suggested that aging has differential effects on the two cerebral hemispheres (Berlingeri et al., 2013), with greater age-related declines in right than left hemisphere function (Benwell et al., 2014), with some studies reporting disproportionate age-related SRT latency increases to stimuli presented in the left visual field (Robinson and Kertzman, 1990).

We analyzed the effects of age, education, sex, handedness, SOA, and hemifield of presentation on SRTs in two large-scale, computer-based experiments incorporating precise timing control. Experiment 1 examined SRTs in a population sample of 1469 New Zealand adults ranging in age from 18 to 65 years. Experiment 2 examined an independent sample of 189 California subjects ranging in age from 18 to 82 years.

\section{Methods: Experiment 1}

As shown in Figure 1, subjects responded as rapidly as possible to stimuli presented to the left or right hemifield by depressing a response button with the index finger of their dominant hand. The task was designed to elicit SRTs with short latencies, and incorporated a number of design features to assure precise SRT measurement: (1) The response button was a computer gaming mouse designed for ultrafast responding with minimum force, displacement, and timing uncertainty; (2) Stimuli were large and of high luminance and contrast; (3) SRT windowing functions excluded response latencies less than $110 \mathrm{~ms}$ and greater than $1000 \mathrm{~ms}$; (4) Twenty practice trials were given to each subject, and SRTs were gathered from 120 test trials; (5) Computer hardware and software delays were measured.

\section{Participants}

We studied a subset of 1637 community volunteers in Rotorua, New Zealand, who had participated in a study of the neuropsychological and health effects of environmental exposure to varying levels of naturally occurring hydrogen sulfide $\left(\mathrm{H}_{2} \mathrm{~S}\right.$; Reed et al., 2014). Because we wanted to compare performance across several neuropsychological tests, we eliminated 75 subjects who lacked complete data sets in the finger tapping (Hubel et al., 2013a), SRT, or choice reaction time (CRT) tests (Woods et al., 2015). We also eliminated 41 ambidextrous subjects whose finger tapping data had not been analyzed, 33 subjects who failed to respond consistently to some types of stimuli in a separate CRT task, and 19 subjects with unexplained poor accuracy on the SRT test (the mean SRT hit-rate for these subjects was 65\%).

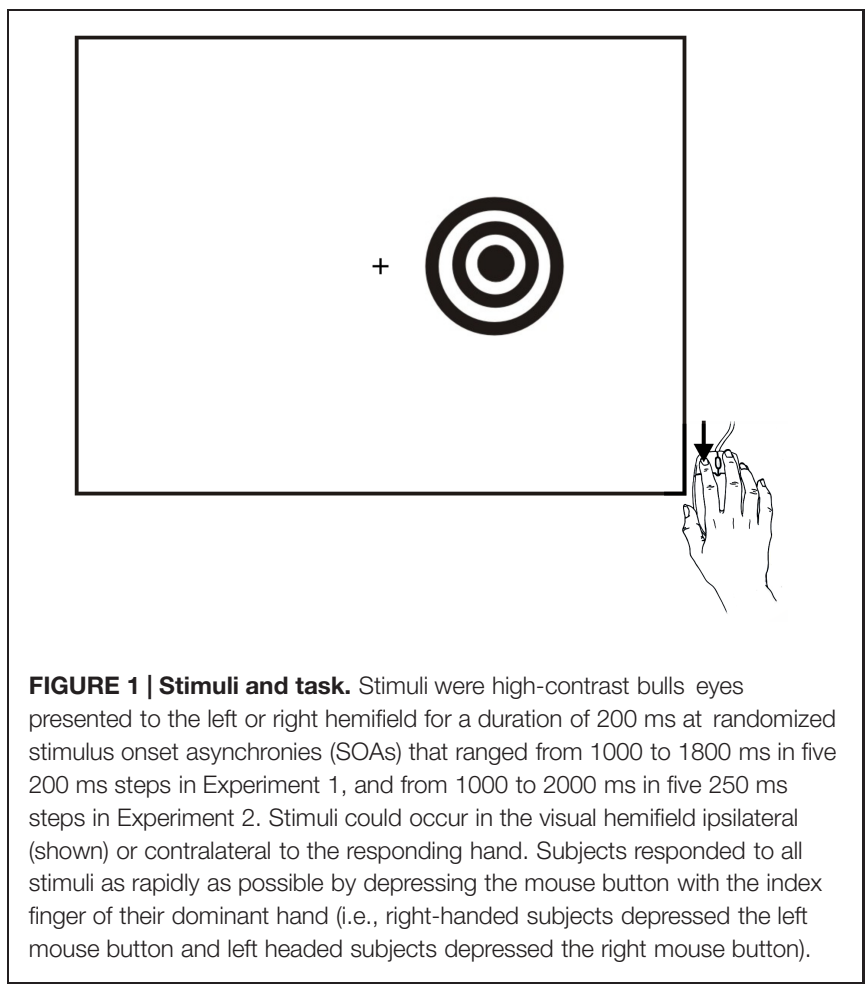

Of the remaining 1469 participants, $40.1 \%$ were men, $10.8 \%$ were left-handed by self-report (based on writing hand), and all were between 18 and 65 years of age (mean age $=46.3$ years. for men, 45.4 years. for women). Participants had an average U.S. equivalent of 12.6 years of education, including $77.1 \%$ who had secondary school qualification, $48.4 \%$ of whom had a qualification beyond secondary school, such as a bachelor's degree $(12.2 \%)$, master's degree $(3.0 \%)$, doctorate $(1.6 \%)$, or other trade, technical, or professional qualification (31.6\%). Most subjects were of European background $(80.0 \%)$ or New Zealand Maori (15.5\%), and 78.8\% were employed. Institutional Review Board approvals for study procedures were obtained at the University of California, Berkeley and from the Northern Ethics Committee in New Zealand. Prior written informed consent was obtained from all participants. Subjects wore prescription lenses as required.

\section{Apparatus and Stimuli}

Simple reaction times were recorded as part of a $30 \mathrm{~min}$. cognitive assessment that included four other tests from the California Cognitive Assessment Battery (CCAB): finger tapping (Hubel et al., 2013a,b), CRT in a visual feature conjunction task (Woods et al., 2015), digit span (Woods et al., 2011a,b), and an adaptive Paced Auditory Serial Addition test. Testing was performed in a quiet room using a PC controlled by Presentation software (Versions 13 and 14, NeuroBehavioral Systems, Albany, CA, USA). Participants practiced for 20 trials before the 120 test trials began, and sat $0.7 \mathrm{~m}$ from a $17^{\prime \prime}$ Samsung Syncmaster LCD monitor, whose refresh rate was $60 \mathrm{~Hz}$. The SRT test and instructions are available online ${ }^{1}$.

${ }^{1}$ www.ebire.org/hcnlab/cognitive-tests/SRT 
Figure 1 shows the stimulus, a black-and-white bull's eye subtending $4^{\circ}$ of visual angle. Stimuli were presented randomly and equiprobably to the left and right hemifield, $3.6^{\circ}$ from a central fixation cross that remained illuminated. Because SRT latencies are influenced by stimulus contrast (Pins and Bonnet, 1996; Ratcliff and Van Dongen, 2011) and brightness (Ratcliff and Van Dongen, 2011; Parker, 2014), stimuli were presented on a bright background $\left(40 \mathrm{~cd} / \mathrm{m}^{2}\right)$ and were of high contrast (dark rings were $0.16 \mathrm{~cd} / \mathrm{m}^{2}$ ). Stimulus durations were fixed at $200 \mathrm{~ms}$. Five different SOAs were used, ranging randomly from 1000 to $1800 \mathrm{~ms}$ in equiprobable, $200 \mathrm{~ms}$ steps. Overall, 24 stimuli were presented at each SOA, half to the left and half to the right hemifield. SRT testing required $\sim 4 \mathrm{~min}$.

\section{Timing Calibration: Hardware and Software Delays}

The precision with which reaction times are collected depends on the computer hardware and software used for measurement (Plant and Turner, 2009). There are two principal sources of hardware delay, which aggregately can inflate true SRT values by up to $100 \mathrm{~ms}$ (Neath et al., 2011). First, there is a delay in the actual appearance of the stimulus after the computer video card sends the stimulus image to the LCD monitor, which depends on monitor electronics. We measured the delay for the Samsung Syncmaster monitor with a photodiode (StimTracker, Cedrus, San Pedro, CA, USA) and found a mean delay of $11.0 \mathrm{~ms}$ $(\mathrm{SD}=0.1 \mathrm{~ms})$. Second, there is a variable delay between the moment that the response button is depressed and the moment that the response is registered by the device driver and detected by the computer software controlling the experiment. For a USB response device, the delay depends on the device design and the device driver software that signals the event to the operating system, and by the frequency with which the stimulus-delivery software polls the driver to determine if a response has occurred. While standard mouse drivers may introduce delays of $20 \mathrm{~ms}$ or more before registering a response, software engineers attempt to minimize such delays when designing mice for computer-gaming applications by shortening the movement required for button closure and writing device drivers with high USB sampling rates. In the current experiment, we used a PC gaming mouse (Razer Sidewinder, Carlsbad, CA, USA) that required minimal movement $(2 \mathrm{~mm})$ for button closure and interfaced with a device driver with a $1.0 \mathrm{kHz}$ USB sampling rate. We measured response delays by disassembling the mouse and simulating button closure with an electronic relay. The average response delay was $6.8 \mathrm{~ms}$ ( $\mathrm{SD}=1.8 \mathrm{~ms})$. Thus, total delays introduced by the video display and mouse averaged $17.8 \mathrm{~ms}$.

In addition to hardware delays, software interruptions can introduce unpredictable delays that may increase SRT latencies and latency variability. The frequency and duration of software interruptions depends on both the design of the stimulus-delivery software and the number and type of extraneous software processes concurrently running on the computer. If a response occurs during an interruption (i.e., when the stimulus-delivery programming has been temporally halted), the occurrence of the response will nevertheless be captured by the response driver, but the latency of the response will not be calculated by the stimulus-delivery program until it returns to execution and samples the response device. These timing interruptions must be continuously monitored throughout an experiment to assure timing precision. Presentation software reports event-time uncertainties for each event during an experiment by continuously sampling the $100 \mathrm{kHz}$ programmable clock. When an extraneous software process interrupts the experiment, there is a corresponding gap in the otherwise continuous event-timing record, and an event occurring during the gap will show a corresponding increase in event-time uncertainty. For example, if a response occurred during a software interruption lasting $10 \mathrm{~ms}$, its latency would be reported as having occurred immediately after the gap, but the associated event-time uncertainty would be $10+\mathrm{ms}$. In the current experiment, the PC was configured to minimize extraneous software interruptions. The analysis of the event-time uncertainties for all $(264,566)$ events that occurred during the experiment showed that software interruptions had a minimal influence on measured SRT latencies: the median event-time uncertainty was $0.1 \mathrm{~ms}$, with $99.9 \%$ of events showing event-time uncertainties of less than $1.05 \mathrm{~ms}$.

\section{Data Analysis}

A response window of 110-1000 ms was used. Responses outside this range were categorized as false alarms (FAs). The failure to respond during the $110-1000 \mathrm{~ms}$ interval following a stimulus was categorized as a miss. Hit rate was defined as the percentage of stimuli associated with valid responses. For each subject, hitrate, false-alarm rate, and mean SRT latency were calculated along with intrasubject (trial-to-trial) SRT variance.

\section{Statistical Analysis}

Participants were classified into seven different 7-year wide age ranges (e.g., from 18-24 years to 59-65 years). The results were first analyzed using a multifactor mixed ANOVA with Age-Group, Sex, SOA, and Hemifield (ipsilateral or contralateral to the preferred responding hand) as independent variables. Separate ANOVAs were performed for mean SRT, hit rate, intrasubject SRT SD, and intrasubject coefficient of variation. Greenhouse-Geisser corrections of degrees of freedom were uniformly used in computing $p$ values in order to correct for any non-spherical covariation within factors or interactions. Effect sizes are reported as $\omega^{2}$ values. Correlation analysis was also used to analyze the effects of age, education, sex, and handedness on SRTs, and to develop age-regression functions. When correlations were significant, a 95\% confidence interval range was calculated with SPSS. Certain pairwise effects were analyzed with Student's $t$-test, using a model that assumes unequal variance in the different subject groups when appropriate.

\section{Results: Experiment 1}

Figure 2 shows Experiment 1 SRT latencies (blue diamonds) as a function of age, and Table 2 shows the different measures for each of the seven age groups and for the entire experiment. An ANOVA for repeated measures showed a significant effect of AgeGroup on SRT $\left[F(6,1462)=15.52, p<0.0002, \omega^{2}=0.06\right]$. SRT 


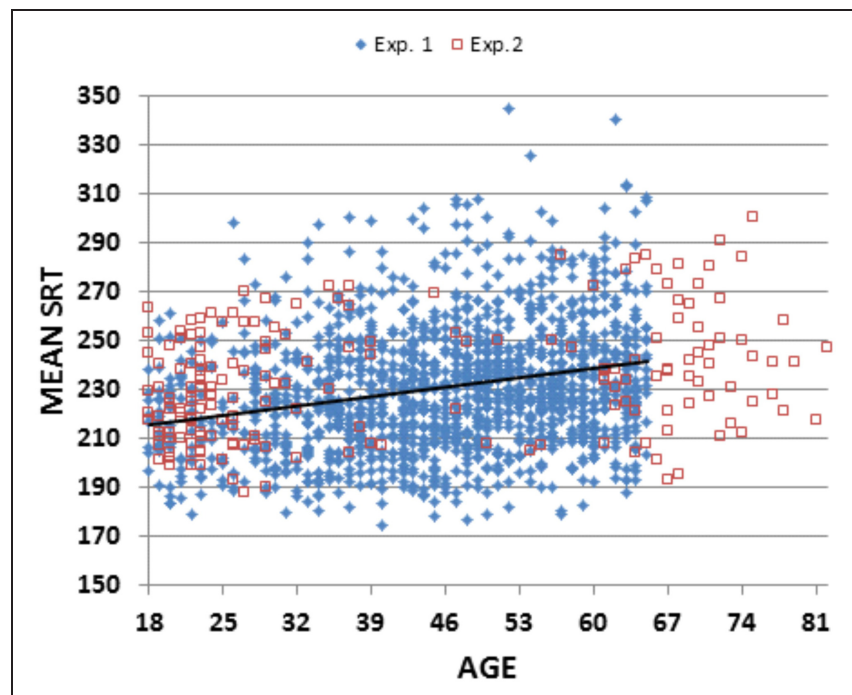

FIGURE 2 | Simple reaction times (SRTs) as a function of age. From subjects in Experiment 1 (blue diamonds) and Experiment 2 (open red squares). Eight subjects from Experiment 1 with mean SRTs above $350 \mathrm{~ms}$ are not shown. The linear trend line is from Experiment 1 data.

latencies were shorter than those seen for the other studies in Table 1. SRT latencies increased from $217.8 \mathrm{~ms}$ (200 ms when latencies were corrected for hardware delays) in the youngest subject group, to $239.1 \mathrm{~ms}$ ( $222.3 \mathrm{~ms}$, delay-corrected) in the oldest subject group. However, the effect size of age was relatively small: power analysis showed that a $99 \%$ probability of detecting a significant $(p<0.05)$ effect of age would require 458 subjects. Age-related slowing occurred throughout the age range, with significant $(p<0.05$, uncorrected) pairwise differences seen between Group 1 (G1) and G3-G7, between G2 and G4-G7, between G3 and G5-G7, between G4 and G5-G7, and between G6 and G7.

Table 3 shows the correlation matrix for Experiment 1. Regression analysis showed significant correlations between age and SRT latencies $[r=0.24$ (range 0.19-0.29), $t(1469)=9.47$, $p<0.0001]$, which showed an age-slope of $0.55 \mathrm{~ms} /$ year. Intraindividual SRT SDs (mean $40.0 \mathrm{~ms}$ ) also showed an effect of Age-Group $\left[F(6,1462)=4.72, p<0.03, \omega^{2}=0.02\right]$, and increased weakly with age $[r=0.11$ (range 0.06-17), $t(1469)=4.24, p<0.0001]$. However, when intrasubject SRT variance was normalized by each individual's SRT latency, the resulting intraindividual coefficient of variation $(\mathrm{CV}$, mean $17.14 \%$ ) did not change significantly with age $[r=0.04]$.

Hit-rate (mean 97.1\%) was also affected by Age-Group $\left[F(6,1462)=16.85, p<0.0001, \omega^{2}=0.06\right]$, and there was a significant correlation between age and hit-rate $[r=0.17$ (range $0.12-0.22), t(1469)=6.61, p<0.0001]$. Both effects were due to reduced hit-rates in the youngest subject group (93.9\%) compared to the other groups (mean 97.2\%), without significant differences between any of the other groups. Hit-rate also correlated with SRT latency $[r=0.25$ (range 0.20-0.30), $t(1467)=9.89$, $p<0.0001]$; i.e., slower subjects were slightly more accurate. Multiple regression showed that both age and hit-rate were independently associated with SRT latency [age, $t(1466)=8.27$, $p<0.0001$; hit-rate, $t(1466)=-8.38, p<0.0001]$.

Subjects made an average of 3.87 FAs (3.2\% of responses). The FA distribution was highly skewed (median $=1.71 \%$, skew $=3.68$ ), with $52.1 \%$ of subjects committing fewer than $2 \%$ FAs, and $5.7 \%$ of subjects producing more than $10 \%$ FAs. There was a strong negative correlation between hit-rate and FA-rate $[r=-0.83, t(1467)=-57.00, p<0.0001]$ : i.e., subjects who made more FAs missed more targets. In addition, increased FA rates were associated with shorter SRT latencies $[r=-0.25, t(1467)=-9.89, p<0.0001]$ and increased SRT variance $[r=0.27, t(1467)=10.74, p<0.0001]$. This likely reflects the occurrence of occasional anticipatory responses within the SRT window, producing very short-latency hits that would both reduce the mean SRT and increase mean SRT variance. Finally, younger subjects (who had lower hit-rates) made more FAs, producing a negative correlation between age and FA-rate $[r=-0.14, t(1467)=-5.42, p<0.0001]$.

TABLE 2 | Age-related changes in performance.

\begin{tabular}{|c|c|c|c|c|c|c|c|c|c|}
\hline Age range & G1: 18-24 & G2: 25-31 & G3: 32-38 & G4: 39-45 & G5: 46-51 & G6: $51-58$ & G7: 59-65 & Experiment 1 & Experiment 2 \\
\hline$N$ & 86 & 115 & 201 & 273 & 276 & 272 & 246 & 1469 & 189 \\
\hline Mean age & 20.8 & 28.6 & 35.5 & 42.3 & 48.6 & 55.0 & 61.6 & 45.8 & 41.0 \\
\hline$\%$ male & $34 \%$ & $36 \%$ & $42 \%$ & $37 \%$ & $41 \%$ & $44 \%$ & $40 \%$ & $40 \%$ & $58 \%$ \\
\hline SRT & 217.9 & 221.0 & 224.8 & 227.7 & 233.6 & 236.4 & 239.1 & 230.8 & 237.8 \\
\hline SRT SD & 19.5 & 22.8 & 23.4 & 26.6 & 27.2 & 27.0 & 28.1 & 26.8 & 27.8 \\
\hline IS-SD & 39.4 & 37.2 & 37.1 & 39.1 & 41.4 & 40.2 & 43.2 & 40.0 & 52.7 \\
\hline $\mathrm{CV}$ & $18 \%$ & $17 \%$ & $16 \%$ & $17 \%$ & $18 \%$ & $17 \%$ & $18 \%$ & $17.1 \%$ & $21.9 \%$ \\
\hline Hit-rate & $93.9 \%$ & $96.7 \%$ & $97.2 \%$ & $97.2 \%$ & $97.6 \%$ & $97.6 \%$ & $97.4 \%$ & $97.1 \%$ & $97.2 \%$ \\
\hline VF-D & 6.76 & 6.97 & 7.84 & 7.63 & 8.40 & 8.30 & 7.16 & 7.74 & 10.5 \\
\hline SDT & 125.8 & 131.8 & 134.0 & 132.6 & 133.5 & 130.2 & 127.7 & 131.2 & 138.3 \\
\hline SOA-D & 30.6 & 25.7 & 27.0 & 29.8 & 27.9 & 27.3 & 29.6 & 28.3 & 26.9 \\
\hline
\end{tabular}

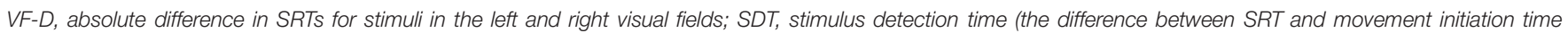

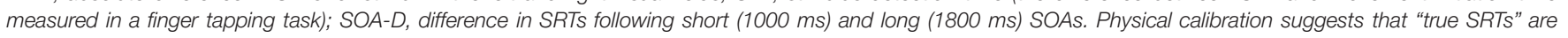
reduced by $18 \mathrm{~ms}$ and SDTs by $11 \mathrm{~ms}$. See Table 1 for descriptions of additional labels. 
TABLE 3 | Correlation matrix for Experiment 1.

\begin{tabular}{|c|c|c|c|c|c|c|c|c|c|}
\hline & Edu & SRT & Hit-rate & AR-SRT & CV & SDT & VF-D & SOA-D & MIT \\
\hline Age & 0.01 & 0.24 & 0.17 & 0.00 & 0.04 & -0.02 & 0.03 & 0.01 & 0.33 \\
\hline Edu & & -0.05 & 0.09 & -0.05 & -0.06 & 0.01 & -0.06 & -0.06 & -0.08 \\
\hline SRT & & & 0.25 & 0.97 & 0.31 & 0.71 & 0.20 & 0.26 & 0.25 \\
\hline Hit-rate & & & & 0.21 & -0.26 & 0.22 & -0.10 & -0.08 & 0.00 \\
\hline AR-SRT & & & & & 0.31 & 0.73 & 0.20 & 0.27 & 0.17 \\
\hline CV & & & & & & 0.19 & 0.19 & 0.16 & 0.12 \\
\hline SDT & & & & & & & 0.03 & 0.01 & -0.51 \\
\hline VF-D & & & & & & & & 0.07 & 0.05 \\
\hline SOA-D & & & & & & & & & 0.05 \\
\hline
\end{tabular}

Given the sample size $(N=1466)$, correlations exceeding $|r|=0.07$ are statistically significant with Bonferroni correction ( $p<0.002)$. MIT, movement initiation time. AR-SRT, age-regressed SRT latency z-score, using the age-regression function from Experiment 2. See Tables $\mathbf{1}$ and $\mathbf{2}$ for descriptions of additional labels.

We examined fatigue effects by comparing SRTs over successive blocks of 20 trials (e.g., 1-20, 21-40, etc.). SRTs increased from $228.1 \mathrm{~ms}$ in the initial 20-trial block, to $237.2 \mathrm{~ms}$ in the final 20-trial block, producing a significant fatigue effect with small effect size $\left[F(5,8165)=88.22, p<0.0001, \omega^{2}=0.05\right]$. The fatigue effect did not correlate with age $[r=-0.01]$, or with any other demographic variable.

Subjects were slightly faster (by $0.61 \mathrm{~ms}$ ) when responding to stimuli presented in the visual field contralateral to the responding hand $\left[F(1,1468)=5.23, p<0.05 \omega^{2}<0.01\right]$. This small effect was not significantly affected by age $[r=-0.05, t(1467)=-1.92$, $p<0.06$ ]. The mean difference between SRT latencies to stimuli presented in the left vs. right visual field was $0.56 \mathrm{~ms}$. This difference was marginally reduced with age $[r=-0.06, t(1467)=2.30$, $p<0.03]$; i.e., this effect was opposite the prediction that older subjects would show a greater increase in slowing for stimuli presented to the left visual field. The absolute value of the difference in SRT latencies to stimuli in the two visual fields was also small $(7.74 \mathrm{~ms})$ and did not vary with age $[r=0.03]$ or sex [r=0.01].

Simple reaction times did not differ significantly between male and female subjects $[F(1,1467)=2.83, p<0.10]$, nor were significant sex differences seen in trial-to-trial SRT variance $[r=-0.01]$ or CVs $[r=0.01]$. Education did not significantly influence SRT latencies $[r=-0.05, t(1467)=1.92, p<0.06]$, but was weakly associated with increases in hit-rate $[r=0.09, t(1467)=3.46$, $p<0.001]$, reduced SRT variance $[r=-0.07, t(1467)=2.69$, $p<0.01]$, and reduced CVs $[r=-0.06, t(1467)=2.30, p<0.03]$. Handedness did not influence SRTs $[r=-0.02]$, SRT variance [ $r=-0.04]$, or SRT CVs $[r=-0.03]$.

Stimulus onset asynchronies had a highly significant effect on SRTs $\left[F(4,5848)=1419.79, p<0.0001, \omega^{2}=0.49\right]$, as shown in Figure 3. SRTs were prolonged (by roughly 15\%) at the shortest SOA. The SOA effect size was large, and power analysis indicated that a $99 \%$ probability of detecting a significant $(p<0.05)$ effect of SOA would require only 10 subjects. Age did not alter SOA effects, with the Age-Group $\times$ SOA interaction failing to reach significance $[F(24,5848)=2.09, p<0.06]$. RT variance also increased at the shortest SOA $[F(4,5848)=126.47, p<0.0001$, $\left.\omega^{2}=0.08\right]$, again without a significant Age-Group $\times$ SOA interaction.

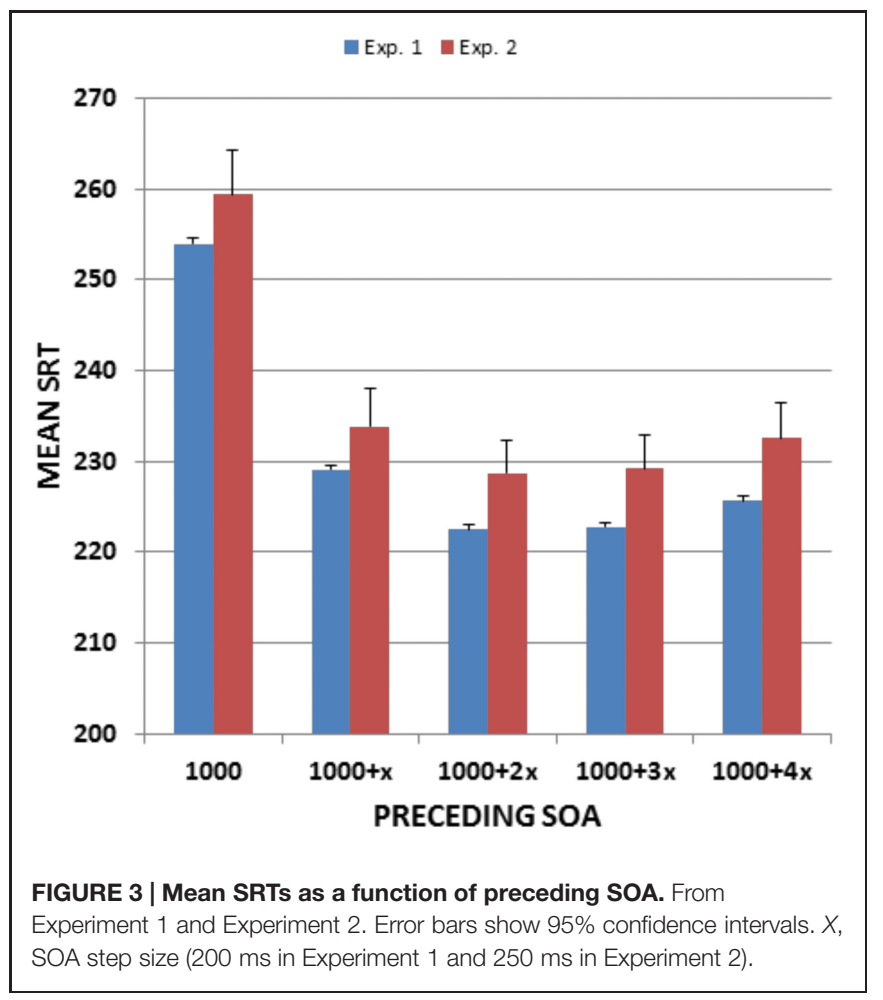

We found a significant correlation $[r=0.25$ (range 0.20-0.30), $t(1,1469)=9.89, p<0.0001]$ between SRT latencies measured in the current experiment and MIT, the time needed to depress the response button that had been previously measured in a self-paced finger tapping task conducted on the same day (Hubel et al., 2013a). SDT latencies, obtained by subtracting MIT latencies from SRT latencies, averaged $131.2 \mathrm{~ms}(\mathrm{SD}=30.2 \mathrm{~ms})$. Figure 4 shows SDT latencies as a function of age. Unlike SRT latencies, SDT latencies did not increase with age $[r=-0.02]$, nor did they differ significantly between male and female subjects $[r=0.05]$. Finally, comparisons of the correlations of age with MIT latency and age with SRT latency showed significantly larger correlations of age with MIT latency $[r=0.33$ vs. $r=0.24$, $z=2.65, p<0.01]$. 


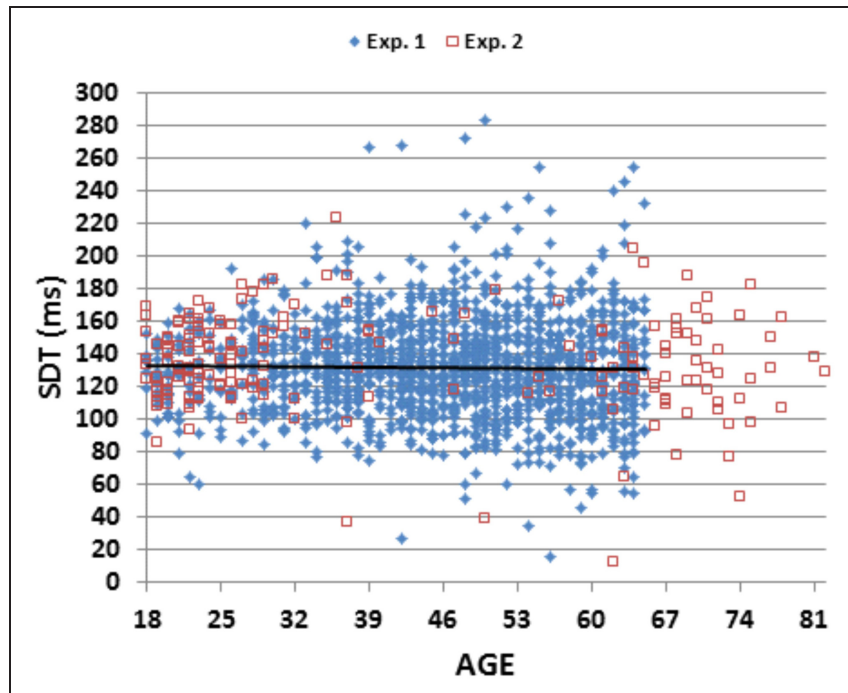

FIGURE 4 | Stimulus detection time (SDT) as a function of age. SDT was derived by subtracting the movement initiation time in a speeded finger tapping test from SRTs. The linear trend line is from Experiment 1 data.

\section{Discussion: Experiment 1}

The mean SRT latencies of 231 ms obtained in the current study were substantially shorter than those reported in most previous computerized SRT studies (Table 1). When corrected for the hardware delays associated with the video display and mouse response $(17.8 \mathrm{~ms})$, "true" SRTs in Experiment 1 ranged from $200 \mathrm{~ms}$ in the youngest subject group to $222 \mathrm{~ms}$ in the oldest, i.e., 15-30 ms above the SRT latencies reported by Galton for subjects of similar age (Johnson et al., 1985). However, based on Galton's notebooks, Dordonova and Dordonov (2013) argued that Galton recorded the shortest-latency SRT obtained out of three independent trials per subject. Assuming a trial-to-trial SRT variance of $50 \mathrm{~ms}$ (see Table 1), Galton's reported single-trial SRT latencies would be $35-43$ ms below the mean SRT latencies predicted for the same subjects; i.e., the mean SRT latencies observed in Experiment 1 would be slightly less than the mean SRT latencies predicted for Galton's subjects. Therefore, in contrast to the suggestions of Woodley et al. (2013), we found no evidence of slowed processing speed in contemporary populations.

Simple reaction time SDs were substantially reduced in comparison to those of previous studies, ranging from 18\% to 55\% of the variances reported in Table 1. Intrasubject (trial-to-trial) SRT variance was also reduced, ranging from $44 \%$ to $69 \%$ of the values reported in previous studies. Within- and between-subject variance measures were likely reduced by the increased precision of SRT measurement, as well as by the number of practice trials, the number of test trials, and the windowing functions used for SRT measurement.

\section{Aging Effects}

Mean SRTs increased with age, with significant differences seen between most adjacent age groups. The age-regression slope of $0.55 \mathrm{~ms} /$ year fell within the range of SRT/age slopes reported in previous studies (range $0.34-1.7 \mathrm{~ms} /$ year, see Table 1). In addition, we found that the youngest subject group made more errors, consistent with suggestions that older subjects are generally more conservative than younger subjects (Forstmann et al., 2011). However, a multiple regression analysis indicated that SRTs showed a highly significant influence of age, even after the influence of hit-rate had been factored out $^{2}$.

Stimulus detection times averaged $131 \mathrm{~ms}$ and did not change with age, suggesting that the rate of accumulation of sensory information (Miller and Ulrich, 2003) was not age-sensitive. The results are consistent with previous modeling studies which show that older subjects accumulate sensory information as rapidly as young subjects, but are delayed in responding (Ratcliff et al., 2001). Interestingly, SDT latencies (120 ms after correcting for display delays in the monitor) were similar to the latencies of early cortical components of the visual evoked potential (Yordanova et al., 2004), which, like SDTs, appear to have stable latencies across the adult life span (Emmerson-Hanover et al., 1994).

Other studies have also suggested that aging effects on SRT latencies are largely the result of slowed motor output. For example, previous electrophysiological studies have found age-related reductions in corticospinal excitability (Levin et al., 2011). In addition, in an SRT task where subjects were required to lift their finger and press a target button following the appearance of a stimulus, Era et al. (2011) found larger age-related changes in the movement phase than in the detection phase. These results imply that SRT tasks that place greater demands on motor responding, for example, by using response buttons that require greater force or displacement for button closure, may enhance the apparent magnitude of age-related slowing, thus contributing to the variability of the age-slopes seen in Table 1.

As in previous studies (Deary and Der, 2005; Der and Deary, 2006; Dykiert et al., 2012a), we found significant increases in SRT variance with age. However, we found no significant age-related changes in the $\mathrm{CV}$, which remained considerably smaller than those reported in previous studies, even in our oldest subject group. One possible explanation is that older subjects require more training to become familiar with the SRT task. As a result, brief tests with limited pre-test training may disproportionately increase variance in older subjects.

\section{SOA and Hemifield Effects}

Stimulus onset asynchrony effects did not differ with age, suggesting that temporal expectancy effects are preserved during normal aging. This finding contrasts with some previous reports (Bherer and Belleville, 2004; Vallesi et al., 2009), but is consistent with others (Greenwood et al., 1993).

\footnotetext{
${ }^{2}$ Experiment 1 data was gathered as part of a study investigating the health effects of chronic exposure to low-level $\mathrm{H}_{2} \mathrm{~S}$ (Reed et al., 2014), which revealed small but significant beneficial effects of $\mathrm{H}_{2} \mathrm{~S}$, such that persons in the highest two quartiles of exposure had SRTs that were $1.8 \mathrm{~ms}$ faster than persons in the lowest exposure quartile. Since age was weakly correlated with exposure $(r=0.035)$, the age regression reported here may slightly underestimate the effect of age on SRT in non- $\mathrm{H}_{2} \mathrm{~S}$ exposed populations.
} 
Both visual-field asymmetries and the absolute value of visual field asymmetries were small and not age-sensitive. SRT latencies showed only a small reduction $(<1 \mathrm{~ms})$ for stimuli presented in the hemifield contralateral to the responding hand, as reported in previous studies (Chaumillon et al., 2014). The latency difference was considerably less than the hypothesized latency $(10+\mathrm{ms})$ required for transcallosal transmission (Caminiti et al., 2009). The small magnitude of the contralateral advantage suggests that visual SRTs may depend on bilateral visual representations at cortical or subcortical levels, rather than on unilateral cortical stimulus processing and transcallosal communication.

\section{Sex Differences}

We found no significant differences between male and female subjects in SRT latencies, SRT variance, CVs, SOA effects, or hemifield effects. A number of previous large-scale studies have found longer SRT latencies in female subjects, along with increased variance and CVs (Fittro et al., 1992; Fozard et al., 1994; Anstey et al., 2005; Dykiert et al., 2012b; Vincent et al., 2012). However, other studies have failed to find significant sex differences (Annett and Annett, 1979; Gottsdanker, 1982; Der and Deary, 2006).

As with aging effects, sex differences may be sensitive to response demands, such as the force or distance needed for button closure. It is well established that the speed of finger tapping is reduced in female subjects, due primarily to an increase in the time that the response button is held down (Hubel et al., 2013a). In a recent study, Era et al. (2011) found larger sex differences in the movement phase than in the detection phase of reaction time studies. Thus, SRT studies that minimize the difficulty of button closure may also reduce sex differences. In addition, sex differences are reportedly reduced with increased familiarity with the task, and may disappear with more extensive practice (Reimers and Maylor, 2006).

\section{Experiment 2: A Replication}

Previous large-scale SRT studies using apparently similar paradigms and subjects have widely varying SRT latencies (Table 1). For example, two studies performed by the same laboratory (Deary et al., 2001, 2011) reported mean SRT latencies that differed by more than $80 \mathrm{~ms}$. Since the mean SRT latencies in Experiment 1 were less than the latencies of most previous studies, a replication of the results in a separate population was needed to evaluate generalizability. Therefore, in Experiment 2, we compared the results of Experiment 1 with the results from a separate population of 189 subjects ranging in age from 18 to 82 years, tested on a different continent.

\section{Methods: Experiment 2}

The methods of Experiment 2 were similar to those in Experiment 1, with two minor modifications. First, SOAs were increased in steps of $250 \mathrm{~ms}$ rather than $200 \mathrm{~ms}$, so that SOAs ranged from 1000 to $2000 \mathrm{~ms}$ in Experiment 2 rather than 1000 to $1800 \mathrm{~ms}$, as in Experiment 1. Second, the SRT test included 100 rather than 120 test trials, while the number of practice trials (20) remained the same.

\section{Participants}

We studied 189 subjects in Experiment 2, whose demographic characteristics are summarized in Table 2. Subjects were recruited from advertisements in the San Francisco Bay Area on Craigslist and from pre-existing control populations, and underwent testing with the entire California Cognitive Assessment Battery $(\mathrm{CCAB})^{3}$. Subjects were required to meet the following inclusion criteria: (a) fluency in the English language; (b) no current or prior history of psychiatric illness; (c) no current substance abuse; (d) no concurrent history of neurologic disease known to affect cognitive functioning; (e) on a stable dosage of any required medication; (f) auditory functioning sufficient to understanding normal conversational speech and visual acuity normal or corrected to 20/40 or better. Subject ethnicities were 64\% Caucasian, 12\% African American, 14\% Asian, 10\% Hispanic/Latino, 2\% Hawaiian/Pacific Islander, 2\% American Indian/Alaskan Native, and $4 \%$ "other."

All subjects signed written consent forms approved by the institutional review board (IRB) at the Veterans Affairs Northern California Health Care System (VANCHCS), and were compensated for their participation. Unlike the subjects in Experiment 1 , who had been recruited as a community sample with balanced age distributions, the age distribution of subjects in Experiment 2 was bimodal: 104 subjects were below the age of 35 years, 24 subjects were between the ages of 35 and 59 years, and 61 subjects were between the ages of 60 and 82 years. The subjects were slightly younger, on average, than those in Experiment $1[t(1656)=4.70, p<0.0001]$, and slightly better educated $[t(1656)=8.64, p<0.0001]$, with an average of 14.6 years of education. Experiment 2 subjects were predominantly male (58\% vs. $40 \%$ in Experiment 1). The 45 subjects over the age of 65 years were particularly well-educated (15.1 years of education). In order to make comparisons between the results of Experiments 1 and 2 with different subject age distributions, we used the ageregression equation from Experiment 1 and calculated $z$-scores in both experiments based on Experiment 1 values.

Identical computer hardware and software were used in the two testing laboratories so that the measured hardware delays were identical to those in Experiment 1. However, because the test computer in Experiment 2 was disconnected from the network, timing uncertainties due to operating system interruptions were reduced compared to those of Experiment 1: median eventtime uncertainties for 62,400 events averaged $0.1 \mathrm{~ms}$ (range 0.1-32.0 ms), with more than $99.9 \%$ of events showing event-time uncertainties of less than $0.3 \mathrm{~ms}$.

\footnotetext{
${ }^{3}$ The CCAB included the following computerized tests and questionnaires: finger tapping, simple reaction time, Stroop, digit span forward and backward, phonemic and semantic verbal fluency, verbal list learning, spatial span, trail making, vocabulary, design fluency, the Wechsler Test of Adult Reading (WTAR), visual feature conjunction, risk and loss avoidance, delay discounting, the Paced Auditory Serial Addition Task (PASAT), the Cognitive Failures Questionnaire (CFQ), the Posttraumatic Stress Disorder Checklist (PCL), and a traumatic brain injury (TBI) questionnaire.
} 


\section{Results: Experiment 2}

The results of Experiment 2 are summarized in Table 2, and data from Experiment 2 (red squares) are included in Figures 2, 3, and 4. Mean SRTs averaged $237.8 \mathrm{~ms}, 7 \mathrm{~ms}$ greater than the mean SRTs of Experiment 1. Applying the age-regression function from Experiment 1 revealed that the SRTs in Experiment 2 were $9.7 \mathrm{~ms}$ above predicted values, producing a small, but significant difference in age-corrected SRT latencies between the two experiments $\left[F(1,1656)=23.24, p<0.0001, \omega^{2}=0.01\right]$. In contrast, hit-rates were virtually identical in the two experiments (97.1 vs. 97.2\%).

The correlation matrix for Experiment 2 is provided in Table 4. As in Experiment 1, there was a significant correlation between age and SRTs $[r=0.35$ (range $0.21-0.48), t(187)=5.11$, $p<0.0001$ ], reflecting an age-slope of $0.45 \mathrm{~ms} /$ year. There was also a significant correlation between age and inter-trial SD $[r=0.33$ (range 0.20-0.47), $t(187)=4.78, p<0.0001]$. However, unlike Experiment 1, there was a significant correlation between age and the CV $[r=0.27$ (range 0.13-0.41), $t(187)=3.84$, $p<0.0002]$.

As in Experiment 1, education had no significant effect on SRT latency $[r=-0.06, t(185)=-0.82$, NS], nor were there significant effects of education on hit-rate, intrasubject SRT latency variance, CVs, or SDTs. Similarly, there were no significant sex differences in SRT latencies, intrasubject SRT variance, CV, or SDTs. However, there was a significant sex difference in hit-rate in Experiment 2: female subjects had slightly higher hit rates than men $[r=-0.23$ (range -0.09 to -0.37 ), $t(187)=3.23$, $p<0.002]$.

Figure 3 shows the effects of preceding SOAs on SRTs. SOA effects were similar to those seen in Experiment 1 $\left[F(4,752)=125.22, p<0.0001, \omega^{2}=0.40\right]$, with SRT latencies reduced by $26.9 \mathrm{~ms}$ at the longest compared to the shortest SOA (versus $28.3 \mathrm{~ms}$ in Experiment 1). As in Experiment 1, SOA effects did not change with age $[r=0.05, t(187)=0.70$, NS]

Subjects were slightly faster to respond to stimuli in the visual field contralateral to the responding hand [by $2.6 \mathrm{~ms}$, $\left.F(1,188)=9.36, p<0.003, \omega^{2}=0.04\right]$. The average difference between SRT latencies in the left and right hemifield remained small $(3.1 \mathrm{~ms})$ and was not significantly correlated with age $[r=0.06, t(187)=0.82$, NS $]$. The absolute value of intrasubject differences in SRTs to stimuli in the left and right visual fields also remained small, although it was slightly larger than the differences seen in Experiment 1 [ 10.5 vs. 7.7 ms, $F(1,1656)=25.59$, $\left.p<0.0001, \omega^{2}=0.01\right]$.

Figure 4 shows SDTs from individual subjects in the two experiments. SDTs were $7 \mathrm{~ms}$ longer in Experiment 2 than Experiment $1\left[F(1,1656)=8.97, p<0.003, \omega^{2}<0.01\right]$. As in Experiment 1, SDT latencies did not change significantly as a function of age $[r=-0.05$, NS]. In contrast, MITs increased with age $[r=0.43$ (range 0.30-0.56), $t(187)=6.51, p<0.0001]$ and, as in Experiment 1, showed a greater correlation with age than SRTs, although the difference in correlation coefficients did not reach significance $[z=0.91, p<0.19]$.

There were several other small but significant differences between Experiment 1 and Experiment 2. Overall, higher values were seen in Experiment 2 for intrasubject SRT latency variance $\left[F(1,1656)=114.21, p<0.0001, \omega^{2}=0.06\right]$ and $C V$ $\left[F(1,1656)=132.49, p<0.0001, \omega^{2}=0.07\right]$. There were also two salient differences in the correlation matrices of the two experiments. Hit-rate increased with age in Experiment $1[r=0.17$, $z=4.68, p<0.0001$ ], but declined with age in Experiment 2 $[r=-0.19, t(187)=2.65, p<0.005]$. Moreover, hit-rate was not significantly correlated with SRT latencies in Experiment 2 $[r=-0.07, \mathrm{NS}]$, unlike the apparent speed/accuracy trade-off $[r=0.25]$ seen in Experiment 1.

\section{Discussion: Experiment 2}

Experiment 2 replicated the results of Experiment 1: mean SRTs differed by only $7 \mathrm{~ms}$ ( 230.8 vs. $237.8 \mathrm{~ms}$ ) between the two studies, and by less than $10 \mathrm{~ms}$ when SRT latencies were corrected for age. The population standard deviations ( $28 \mathrm{vs} .27 \mathrm{~ms}$ ) were also very similar in the two studies. The small difference in mean SRTs in the two experiments likely reflected the slightly increased mean and dispersion of SOAs in Experiment 2 (Niemi and Naatanen, 1981). Increased SOA dispersion may also have contributed to the increase in Experiment 2 intrasubject SRT variability and CV, which may also have been inflated due to the slight reduction in the number of test trials.

TABLE 4 | Correlation matrix for Experiment 2.

\begin{tabular}{|c|c|c|c|c|c|c|c|c|c|}
\hline & Edu & SRT & Hit-rate & AR-SRT & CV & SDT & D-VF & D-SOA & MIT \\
\hline Edu & & -0.06 & -0.10 & -0.13 & -0.11 & 0.01 & -0.03 & -0.02 & -0.06 \\
\hline Hit-rate & & & & 0.01 & -0.44 & 0.09 & -0.19 & 0.08 & -0.17 \\
\hline AR-SRT & & & & & 0.25 & 0.65 & 0.30 & 0.18 & 0.14 \\
\hline CV & & & & & & 0.02 & 0.12 & 0.50 & 0.32 \\
\hline DVF & & & & & & & & -0.19 & -0.07 \\
\hline D-SOA & & & & & & & & & 0.17 \\
\hline
\end{tabular}

Given the sample size $(N=189)$, correlations exceeding $|r|=0.20$ are statistically significant with Bonferroni correction $(p<0.002)$. See previous tables for descriptions of additional labels. 
Highly significant age-related SRT slowing was also seen in both studies, with correlation coefficients of moderate magnitude [ $r=0.24$ and $r=0.35]$ and similar slopes $(0.55 \mathrm{~ms} /$ year and $0.45 \mathrm{~ms} /$ year). In both experiments, SDT latencies did not change systematically with age. Since the MIT was estimated from a separate finger tapping task, any changes in the SRT latencies would be included in the SDT, i.e., the SRT-MIT difference. Therefore, the SDT would be expected to increase with SOA manipulations that prolong SRTs (Anstey et al., 2005). In both experiments, MITs showed greater correlations with age than did SRTs. Other factors, including sex and education, had minimal effects on performance in either experiment. Finally, the preceding SOA had a strong influence on SRT latencies in both experiments (effect sizes of 0.49 and 0.40 ), with SRTs being prolonged by 28 and $27 \mathrm{~ms}$, respectively.

Importantly, SRT latencies across the two experiments were more consistent than in previous large-scale SRT replications, with the small differences in SRT latencies largely explained by the change in the range of SOAs. Other experiments, using apparently similar SRT paradigms and apparatus, have obtained more disparate results. For example, using a similar paradigm, Deary and Der (2005) reported mean SRTs of $328 \mathrm{~ms}$, Deary et al. (2001) reported mean SRTs of $358 \mathrm{~ms}$, Deary et al. (2011) reported mean SRTs of $256 \mathrm{~ms}$, and Dykiert et al. (2012b) reported mean SRTs of $275 \mathrm{~ms}$. As seen in Table 1, the mean SRTs from Deary et al. (2001) were roughly 2.7 SDs above the mean SRTs collected by Dykiert et al. (2012b). SRT latency replicability was better in studies with the ANAM military test battery. In the largest study, Vincent et al. (2012) reported SRTs of $261 \mathrm{~ms}$, while Reeves et al. (2006) tested a population with a slightly lower mean age and reported SRTs of $285 \mathrm{~ms}$; the SRT latency differences between these two studies, $24 \mathrm{~ms}$, was more than three times the differences that we observed, and was accompanied by relatively large differences in both population standard deviations and age/SRT slopes. In contrast, the differences in SRTs between Experiment 1 and Experiment 2 were small in both absolute and age-corrected magnitude, and both experiments produced similar population SDs and age/SRT slopes. This suggests that the use of high-precision computer hardware and software can improve the precision and replicability of SRT latency measures.

\section{General Discussion}

Delay-corrected SRT latencies were substantially shorter (213 and $220 \mathrm{~ms}$ in Experiments 1 and 2, respectively) than the SRT latencies reported in other large-scale computer-based studies, but were similar to the SRT latencies reported both by Galton (Johnson et al., 1985) and contemporary researchers using noncomputerized measures (Eckner et al., 2011; Montare, 2013). Thus, unlike Woodley et al. (2013), we found no evidence of slowed processing speed in the contemporary populations that we tested.

The origin of the large variations in SRT latencies seen in recent computerized studies remains obscure. Differences in computer hardware and software (Plant and Turner, 2009) can, in some circumstances, add up to $100 \mathrm{~ms}$ to mean SRT latency measurements (Neath et al., 2011), and software interruptions could also increase latency measures and trial-to-trial SRT latency variability. In addition, visual SRTs are influenced by the SRT windowing function, the temporal pattern of stimulus delivery, stimulus luminance and contrast, and by the force and distance needed to activate the response button. Many of these variables have not been reported in previous SRT studies, and may have differed in experiments that used apparently similar methods.

\section{The Effects of Age on SRT Latencies}

We found highly significant correlations of moderate magnitude between age and SRT latencies in both studies. The rate of agerelated SRT slowing that we observed (mean $0.50 \mathrm{~ms} /$ year) was similar to that of Dykiert et al. (2012a), but considerably less than the slowing observed in other SRT studies (Deary and Der, 2005; Reeves et al., 2007; Vincent et al., 2008; Deary et al., 2011). We also found significant age-related increases in SRT variance, and, in Experiment 2, increases in the CV as well, consistent with previous reports (Dykiert et al., 2012a).

The nature of aging effects was further clarified by analyzing SDT latencies, which were not influenced by age in either study. This suggests that the age-related slowing of SRTs was largely due to the additional time required by older subjects to depress the response button, a hypothesis supported by stronger correlations observed in both studies between age and the MIT than between age and SRT latencies.

\section{Sex Differences}

Sex differences have been found in mean SRTs and intrasubject SRT variability in a number of previous studies (Deary et al., 2001; Der and Deary, 2006; Dykiert et al., 2012b). In contrast, we found no sex differences in SRT latencies, nor did we find significant sex differences in intrasubject reaction time variance in either experiment. In this regard, Silverman (2006) reviewed studies of sex differences in SRTs performed throughout the 20th century. He found that the magnitude of reported sex differences declined markedly by the late 20 th century, and speculated that reduced sex differences reflected increased opportunities for female participation in fast-action sports and driving.

\section{Conclusion}

When measured with high-precision computer hardware and software, SRTs were obtained with short latencies (ca. $235 \mathrm{~ms}$ ) that were similar across two large subject populations. When corrected for hardware and software delays, SRT latencies in young subjects were similar to those estimated from Galton's historical studies, and provided no evidence of slowed processing speed in modern populations. SRTs to lateralized stimuli had slightly shorter latencies when the stimuli were presented in the visual field contralateral to the responding hand. However, the latency differences $(<3 \mathrm{~ms})$ were smaller than the delays expected from transcallosal transmission. SRTs increased with age at a rate of $\sim 0.5 \mathrm{~ms} /$ year, but were not significantly influenced by education or sex. The latency of stimulus detection, estimated from the difference in SRTs and movement initiation times measured in a 
finger tapping task, was stable across adulthood, suggesting that the age-related slowing of SRTs primarily reflected slowed motor output.

\section{Acknowledgments}

This research was supported by a VA Research Service Grants CX000583 and CX001000 to DW and Award R01ES014038

\section{References}

Annett, M., and Annett, J. (1979). Individual differences in right and left reaction time. Br. J. Psychol. 70, 393-404. doi: 10.1111/j.2044-8295.1979.tb01709.x

Anstey, K. J., Dear, K., Christensen, H., and Jorm, A. F. (2005). Biomarkers, health, lifestyle, and demographic variables as correlates of reaction time performance in early, middle, and late adulthood. Q. J. Exp. Psychol. A 58, 5-21. doi: 10.1080/02724980443000232

Benwell, C. S., Thut, G., Grant, A., and Harvey, M. (2014). A rightward shift in the visuospatial attention vector with healthy aging. Front. Aging Neurosci. 6:113. doi: 10.3389/fnagi.2014.00113

Berlingeri, M., Danelli, L., Bottini, G., Sberna, M., and Paulesu, E. (2013). Reassessing the HAROLD model: is the hemispheric asymmetry reduction in older adults a special case of compensatory-related utilisation of neural circuits? Exp. Brain Res. 224, 393-410. doi: 10.1007/s00221-012-3319-x

Bherer, L., and Belleville, S. (2004). Age-related differences in response preparation: the role of time uncertainty. J. Gerontol. B Psychol. Sci. Soc. Sci. 59, P66-P74. doi: 10.1093/geronb/59.2.P66

Bielak, A. A., Cherbuin, N., Bunce, D., and Anstey, K. J. (2014). Intraindividual variability is a fundamental phenomenon of aging: evidence from an 8-year longitudinal study across young, middle, and older adulthood. Dev. Psychol. 50, 143-151. doi: 10.1037/a0032650

Bisiacchi, P., Marzi, C. A., Nicoletti, R., Carena, G., Mucignat, C., and Tomaiuolo, F. (1994). Left-right asymmetry of callosal transfer in normal human subjects. Behav. Brain Res. 64, 173-178. doi: 10.1016/0166-4328(94) 90129-5

Brizzolara, D., Ferretti, G., Brovedani, P., Casalini, C., and Sbrana, B. (1994). Is interhemispheric transfer time related to age? A developmental study. Behav. Brain Res. 64, 179-184. doi: 10.1016/0166-4328(94)90130-9

Bugg, J. M., Zook, N. A., Delosh, E. L., Davalos, D. B., and Davis, H. P. (2006). Age differences in fluid intelligence: contributions of general slowing and frontal decline. Brain Cogn. 62, 9-16. doi: 10.1016/j.bandc.2006.02.006

Caminiti, R., Ghaziri, H., Galuske, R., Hof, P. R., and Innocenti, G. M. (2009). Evolution amplified processing with temporally dispersed slow neuronal connectivity in primates. Proc. Natl. Acad. Sci. U.S.A. 106, 19551-19556. doi: 10.1073/pnas.0907655106

Chaumillon, R., Blouin, J., and Guillaume, A. (2014). Eye dominance influences triggering action: the Poffenberger paradigm revisited. Cortex 58, 86-98. doi: 10.1016/j.cortex.2014.05.009

Clarke, J. M., and Zaidel, E. (1989). Simple reaction times to lateralized light flashes. Varieties of interhemispheric communication routes. Brain 112(Pt 4), 849-870. doi: 10.1093/brain/112.4.849

Commodari, E., and Guarnera, M. (2008). Attention and aging. Aging Clin. Exp. Res. 20, 578-584. doi: 10.1007/BF03324887

Deary, I. J., and Der, G. (2005). Reaction time, age, and cognitive ability: longitudinal findings from age 16 to 63 years in representative population samples. Aging Neuropsychol. Cogn. 12, 187-215. doi: 10.1080/138255805909 69235

Deary, I. J., Der, G., and Ford, G. (2001). Reaction times and intelligence differences: a population-based cohort study. Intelligence 29, 389-399. doi: 10.1016/S0160-2896(01)00062-9

Deary, I. J., Johnson, W., and Starr, J. M. (2010). Are processing speed tasks biomarkers of cognitive aging? Psychol. Aging 25, 219-228. doi: $10.1037 / \mathrm{a} 0017750$ from the National Institute of Environmental Health Sciences to Michael Bates. The content is solely the responsibility of the authors and does not necessarily represent the official views of the funding agencies. We would also like to thank Ben Edwards, Oran Poliva, Masood Younus, Nabeel Rahman, Kerry Hubel, Nerene Lynskey, Kataraina George, and John McKeogh, who helped to gather the data used in this report, and to Robert Hink, who developed the MySQL database.

Deary, I. J., Liewald, D., and Nissan, J. (2011). A free, easy-to-use, computerbased simple and four-choice reaction time programme: the Deary-Liewald reaction time task. Behav. Res. Methods 43, 258-268. doi: 10.3758/s13428-0100024-1

Der, G., and Deary, I. J. (2006). Age and sex differences in reaction time in adulthood: results from the United Kingdom Health and Lifestyle Survey. Psychol. Aging 21, 62-73. doi: 10.1037/0882-7974.21.1.62

Dordonova, Y. A., and Dordonov, Y. S. (2013). Is there any evidence of historical slowing of reaction time? No, unless we compare apples and oranges. Intelligence 41, 674-687. doi: 10.1016/j.intell.2013.09.001

Dykiert, D., Der, G., Starr, J. M., and Deary, I. J. (2012a). Age differences in intraindividual variability in simple and choice reaction time: systematic review and meta-analysis. PLoS ONE 7:e45759. doi: 10.1371/journal.pone.0045759

Dykiert, D., Der, G., Starr, J. M., and Deary, I. J. (2012b). Sex differences in reaction time mean and intraindividual variability across the life span. Dev. Psychol. 48, 1262-1276. doi: 10.1037/a0027550

Eckner, J. T., Kutcher, J. S., and Richardson, J. K. (2011). Between-seasons testretest reliability of clinically measured reaction time in National Collegiate Athletic Association Division I athletes. J. Athl. Train. 46, 409-414.

Emmerson-Hanover, R., Shearer, D. E., Creel, D. J., and Dustman, R. E. (1994). Pattern reversal evoked potentials: gender differences and age-related changes in amplitude and latency. Electroencephalogr. Clin. Neurophysiol. 92, 93-101. doi: 10.1016/0168-5597(94)90049-3

Era, P., Sainio, P., Koskinen, S., Ohlgren, J., Harkanen, T., and Aromaa, A. (2011). Psychomotor speed in a random sample of 7,979 subjects aged 30 years and over. Aging Clin. Exp. Res. 23, 135-144. doi: 10.1007/BF03351077

Fittro, K. P., Bolla, K. I., Heller, J. R., and Meyd, C. J. (1992). The Milan Automated Neurobehavioral System. Age, sex, and education differences. J. Occup. Med. 34, 918-922.

Forstmann, B. U., Tittgemeyer, M., Wagenmakers, E. J., Derrfuss, J., Imperati, D., and Brown, S. (2011). The speed-accuracy tradeoff in the elderly brain: a structural model-based approach. J. Neurosci. 31, 17242-17249. doi: 10.1523/JNEUROSCI.0309-11.2011

Fozard, J. L., Vercryssen, M., Reynolds, S. L., Hancock, P. A., and Quilter, R. E. (1994). Age differences and changes in reaction time: the Baltimore Longitudinal Study of Aging. J. Gerontol. 49, P179-P189. doi: 10.1093/geronj/49.4.P179

Godefroy, O., Roussel, M., Despretz, P., Quaglino, V., and Boucart, M. (2010). Agerelated slowing: perceptuomotor, decision, or attention decline? Exp. Aging Res. 36, 169-189. doi: 10.1080/03610731003613615

Gottsdanker, R. (1982). Age and simple reaction time. J. Gerontol. 37, 342-348. doi: 10.1093/geronj/37.3.342

Greenwood, P. M., Parasuraman, R., and Haxby, J. V. (1993). Changes in visuospatial attention over the adult lifespan. Neuropsychologia 31, 471-485. doi: 10.1016/0028-3932(93)90061-4

Hubel, K. A., Reed, B., Yund, E. W., Herron, T. J., and Woods, D. L. (2013a). Computerized measures of finger tapping: effects of hand dominance, age, and sex. Percept. Mot. Skills 116, 929-952. doi: 10.2466/25.29.PMS.116.3.929-952

Hubel, K. A., Yund, E. W., Herron, T. J., and Woods, D. L. (2013b). Computerized measures of finger tapping: reliability, malingering and traumatic brain injury. J. Clin. Exp. Neuropsychol. 35, 745-758. doi: 10.1080/13803395.2013. 824070

Inui, N. (1997). Simple reaction times and timing of serial reactions of middle-aged and old men. Percept. Mot. Skills 84, 219-225. doi: 10.2466/pms.1997.84.1.219 
Jensen, A. R. (2011). The theory of intelligence and its measurement. Intelligence 39, 171-177. doi: 10.1016/j.intell.2011.03.004

Johnson, R. C., Mcclearn, G. E., Yuen, S., Nagoshi, C. T., Ahern, F. M., and Cole, R. E. (1985). Galton's data a century later. Am. Psychol. 40, 875-892. doi: 10.1037/0003-066X.40.8.875

Krieg, E. F. Jr., Chrislip, D. W., Letz, R. E., Otto, D. A., Crespo, C. J., Brightwell, $\mathrm{N}$, S., et al. (2001). Neurobehavioral test performance in the third National Health and Nutrition Examination Survey. Neurotoxicol. Teratol. 23, 569-589. doi: 10.1016/S0892-0362(01)00177-5

Levin, O., Cuypers, K., Netz, Y., Thijs, H., Nuttin, B., Helsen, W. F., et al. (2011). Age-related differences in human corticospinal excitability during simple reaction time. Neurosci. Lett. 487, 53-57. doi: 10.1016/j.neulet.2010.09.072

Lowe, C., and Rabbitt, P. (1998). Test/re-test reliability of the CANTAB and ISPOCD neuropsychological batteries: theoretical and practical issues. Cambridge Neuropsychological Test Automated Battery. International Study of Post-Operative Cognitive Dysfunction. Neuropsychologia 36, 915-923. doi: 10.1016/S0028-3932(98)00036-0

Miller, J., and Ulrich, R. (2003). Simple reaction time and statistical facilitation: a parallel grains model. Cogn. Psychol. 46, 101-151. doi: 10.1016/S00100285(02)00517-0

Montare, A. (2010). The simplest chronoscope II: reaction time measured by meterstick versus machine. Percept. Mot. Skills 111, 819-828. doi: 10.2466/03.15.25.PMS.111.6.819-828

Montare, A. (2013). Simplest chronoscope. III: further comparisons between reaction times obtained by meterstick versus machine. Percept. Mot. Skills 116, 796-805. doi: 10.2466/27.24.PMS.116.3.796-805

Neath, I., Earle, A., Hallett, D., and Surprenant, A. M. (2011). Response time accuracy in Apple Macintosh computers. Behav. Res. Methods 43, 353-362. doi: 10.3758/s13428-011-0069-9

Niemi, P., and Naatanen, R. (1981). Foreperiod and simple reaction time. Psychol. Bull. 89, 133-162. doi: 10.1037/0033-2909.89.1.133

Parker, S. (2014). Were the Victorians cleverer than us? Maybe, maybe not. Intelligence 47, 1-2. doi: 10.1016/j.intell.2014.08.002

Pins, D., and Bonnet, C. (1996). On the relation between stimulus intensity and processing time: Piéron's law and choice reaction time. Percept. Psychophys. 58, 390-400. doi: 10.3758/BF03206815

Plant, R. R., and Turner, G. (2009). Millisecond precision psychological research in a world of commodity computers: new hardware, new problems? Behav. Res. Methods 41, 598-614. doi: 10.3758/BRM.41.3.598

Ratcliff, R., Thapar, A., and Mckoon, G. (2001). The effects of aging on reaction time in a signal detection task. Psychol. Aging 16, 323-341. doi: 10.1037/08827974.16.2.323

Ratcliff, R., and Van Dongen, H. P. (2011). Diffusion model for one-choice reaction-time tasks and the cognitive effects of sleep deprivation. Proc. Natl. Acad. Sci. U.S.A. 108, 11285-11290. doi: 10.1073/pnas.1100483108

Reed, B. R., Crane, J., Garrett, N., Woods, D. L., and Bates, M. N. (2014). Chronic ambient hydrogen sulfide exposure and cognitive function. Neurotoxicol. Teratol. 42, 68-76. doi: 10.1016/j.ntt.2014.02.002

Reeves, D. L., Bleiberg, J., Roebuck-Spencer, T., Cernich, A. N., Schwab, K., Ivins, B., et al. (2006). Reference values for performance on the Automated Neuropsychological Assessment Metrics V3.0 in an active duty military sample. Mil. Med. 171, 982-994.

Reeves, D. L., Winter, K. P., Bleiberg, J., and Kane, R. L. (2007). ANAM genogram: historical perspectives, description, and current endeavors. Arch. Clin. Neuropsychol. 22(Suppl. 1), S15-S37. doi: 10.1016/j.acn.2006.10.013

Reimers, S., and Maylor, E. A. (2006). Gender effects on reaction time variability and trial-to-trial performance: reply to Deary and Der (2005).
Neuropsychol. Dev. Cogn. B Aging Neuropsychol. Cogn. 13, 479-489. doi: 10.1080/138255890969375

Ritchie, S. J., Bates, T. C., Der, G., Starr, J. M., and Deary, I. J. (2013). Education is associated with higher later life IQ scores, but not with faster cognitive processing speed. Psychol. Aging 28, 515-521. doi: 10.1037/a0030820

Robinson, D. L., and Kertzman, C. (1990). Visuospatial attention: effects of age, gender, and spatial reference. Neuropsychologia 28, 291-301. doi: 10.1016/00283932(90)90022-G

Sheppard, L., and Vernon, P. A. (2008). Intelligence and speed of informationprocessing: a review of 50 years of research. Pers. Individ. Dif. 44, 535-551. doi: 10.1016/j.paid.2007.09.015

Silverman, I. W. (2006). Sex differences in simple visual reaction time: a historical meta-analysis. Sex Roles 54, 58-68. doi: 10.1007/s11199-006-8869-6

Silverman, I. W. (2010). Simple reaction time: it is not what it used to be. Am. J. Psychol. 123, 39-50. doi: 10.5406/amerjpsyc.123.1.0039

Vallesi, A., Mcintosh, A. R., and Stuss, D. T. (2009). Temporal preparation in aging: a functional MRI study. Neuropsychologia 47, 2876-2881. doi: 10.1016/j.neuropsychologia.2009.06.013

Vincent, A. S., Bleiberg, J., Yan, S., Ivins, B., Reeves, D. L., Schwab, K., et al. (2008). Reference data from the automated Neuropsychological Assessment Metrics for use in traumatic brain injury in an active duty military sample. Mil. Med. 173, 836-852. doi: 10.7205/MILMED.173.9.836

Vincent, A. S., Roebuck-Spencer, T., Gilliland, K., and Schlegel, R. (2012). Automated neuropsychological assessment metrics (v4) traumatic brain injury battery: military normative data. Mil. Med. 177, 256-269. doi: 10.7205/MILMED-D-11-00289

Wilkinson, R. T., and Allison, S. (1989). Age and simple reaction time: decade differences for 5,325 subjects. J. Gerontol. 44, P29-P35. doi: 10.1093/geronj/44.2.P29

Woodley, M. A., Nijenhuis, T., and Murphy, R. (2013). Were the Victorians cleverer than us? The decline in general intelligence estimated from a metaanalysis of the slowing of simple reaction time. Intelligence 41, 843-850. doi: 10.1016/j.intell.2013.04.006

Woods, D. L., Kishiyama, M. M., Yund, E. W., Herron, T. J., Edwards, B., Poliva, O., et al. (2011a). Improving digit span assessment of short-term verbal memory. J. Clin. Exp. Neuropsychol. 33, 101-111. doi: 10.1080/13803395.2010. 493149

Woods, D. L., Kishiyama, M. M., Yund, E. W., Herron, T. J., Hink, R. F., and Reed, B. (2011b). Computerized analysis of error patterns in digit span recall. J. Clin. Exp. Neuropsychol. 33, 721-734. doi: 10.1080/13803395.2010.550602

Woods, D. L., Wyma, J., Yund, E. W., Herron, T. J., and Reed, B. (2015). The effects of aging on visual choice reaction time. Front. Hum. Neurosci. (in press).

Yordanova, J., Kolev, V., Hohnsbein, J., and Falkenstein, M. (2004). Sensorimotor slowing with ageing is mediated by a functional dysregulation of motorgeneration processes: evidence from high-resolution event-related potentials. Brain 127, 351-362. doi: 10.1093/brain/awh042

Conflict of Interest Statement: David L. Woods is affiliated with NeuroBehavioral Systems, Inc., the developers of Presentation software used to create these experiments.

Copyright () 2015 Woods, Wyma, Yund, Herron and Reed. This is an open-access article distributed under the terms of the Creative Commons Attribution License (CC BY). The use, distribution or reproduction in other forums is permitted, provided the original author(s) or licensor are credited and that the original publication in this journal is cited, in accordance with accepted academic practice. No use, distribution or reproduction is permitted which does not comply with these terms. 